\title{
Citra tubuh, Perilaku Diet, dan Kualitas Hidup Remaja Akhir Mahasiswa Fakultas Kedokteran Universitas Riau
}

\author{
Lilly Haslinda ${ }^{1}$, Yanti Ernalia² ${ }^{2}$, Sri Wahyuni ${ }^{2}$
}

\begin{abstract}
Late adolescence (17-20 years) is when a child has made a career decision in the future. Body image in adolescents associated with eating disorders and psychological problems such as depression. Nutritional status is well aligned with the quality of life of adolescents. This study aims to determine the body image, dietary behavior, and quality of life in the period of late adolescence students of the Faculty of Medicine, University of Riau. This study was a crosssectional analytical study conducted at the end of the 87 teenage students of the Faculty of Medicine, University of Riau. Selection of the subject of research conducted with total sampling. Measurements made with the body image questionnaire silhouettes body image, dietary behavioral data with the questionnaire (eating attitude test) / EAT-26, and the data Quality of Life with WHO-QOL questionnaire. Furthermore, the data presented descriptively. Of the 87 respondents there were 25.3\% (22) male subjects and 74.7\% (65) female subjects. Based on BMI, there are more nutritional status (overweight and obesity) of 27.6\%, less nutritional status (underweight) 17.2\%. Based on abdominal circumference there are $25.3 \%$ subjects felt obesity there are $51.7 \%$ research subjects who felt dissatisfied with her body image. A total of 36.8\% of research subjects perceive their bodies emaciated, 19.5\% perceive overweight and $1.2 \%$ obese perceived body image. A total of $9.2 \%$ of the subjects experienced the possibility of eating behavior disorders. There are $43.7 \%$ of research subjects who have less quality of life.
\end{abstract}

Keywords: Late Teens, Body Image, Dietary Behavior, Quality of Life

Remaja merupakan periode peralihan dari masa anak-anak ketahap dewasa. Banyak perubahan yang terjadi pada remaja termasuk perubahan sikap, perubahan cara berfikir, dan pertambahan fisik yang pesat selain periode awal kelahiran. Perubahan sikap dan cara berfikir pada remaja akan membentuk harga diri remaja (self-esteem). Self-esteem berhubungan dengan ketidapuasan terhadap citra tubuh pada remaja dan pola makan. Remaja yang sangat tidak puas terhadap citra tubuh dan pola makannya diketahui memiliki harga diri yang rendah dan secara umum sangat tidak puas terhadap aspek kehidupannya. ${ }^{1}$

Masa remaja akhir mencakup usia 17 tahun sampai dengan 20 tahun. Ciri somatik yang timbul pada masa ini yaitu pertumbuhan lebih lambat.

\footnotetext{
1. Penulis untuk korespondensi : Bagian Parasitologi Fakultas Kedokteran Universitas Riau

2. Bagian Gizi Fakultas Kedokteran Universitas Riau.
}

Perkembangan seksual yang paling menonjol adalah konsolidasi identitas seksual. Hubungan dengan masyarakat sudah jauh berkembang pada masa ini kerena pada masa inilah seorang anak sudah membuat keputusan karir di masa depan. ${ }^{2}$

Banyak faktor yang berhubungan dengan alasan remaja melakukan diet. Faktor individu, keluarga dan lingkungan berperan terhadap perilaku diet pada remaja, namun ketidakpuasan citra tubuh dan motivasi menjadi lebih kurus merupakan faktor terbesar. ${ }^{3}$ Sudah bukan suatu hal yang baru, bahwa ternyata citra tubuh pada remaja berhubungan dengan gangguan makan dan masalah psikologi seperti depresi. ${ }^{4}$

Permasalahan mengenai citra tubuh ini menjadi perhatian khusus pada anak remaja, hal ini karena dari penelitian-penelitian sebelumnya segala hal permasalahan akibat persepsi yang salah mengenai citra tubuh yang terjadi massa remaja akan terus berlanjut hingga ke usia dewasa. ${ }^{5} \mathrm{Di}$ daerah 
perkotaan remaja lebih banyak terkena paparan media yang semakin berkembang. Media massa berkontribusi terhadap kejadian overweight dan eating disorders pada remaja. ${ }^{6}$

Remaja yang mengalami obesitas biasanya pasif dan depresif, karena sering tidak dilibatkan pada kegiatan yang dilakukan oleh teman sebayanya. ${ }^{2}$ Beberapa penelitian menyatakan adanya hubungan antara obesitas dengan kualitas hidup pada anak dan remaja. Rata-rata kualitas hidup anak yang mengalami obesitas lebih rendah dibandingkan dengan rata-rata kualitas hidup anak yang tidak mengalami obesitas. ${ }^{7}$ Kualitas hidup adalah persepsi individu terhadap kondisi kehidupan dalam konteks budaya dan sistem nilai di tempat seseorang hidup dan dihubungkan dengan tujuan, harapan, standar dan perhatian yang dimiliki. ${ }^{8}$

Permasalahan mengenai kecukupan asupan gizi remaja di Indonesia masih jarang diteliti, padahal pada tahap ini terjadi pertumbuhan fisik yang cepat. Hal ini menjadi suatu alasan yang sangat penting agar dilakukan penelitian lebih lanjut mengenai citra tubuh, perilaku diet, dan kualitas hidup remaja akhir mahasiswa fakultas kedokteran universitas riau

\section{METODE}

Penelitian ini menggunakan metode deskriptif. Penelitian ini akan dilakukan di Universitas Riau selama enam bulan dari bulan Juni-November 2013. Populasi Umum adalah seluruh mahasiswa Fakultas Kedokteran Universitas Riau pada Tahun Ajaran 2013/2014. Populasi target dan terjangkau adalah mahasiswa Fakultas Kedokteran Universitas Riau yang berada pada periode remaja akhir berusia 17-20 Tahun. Subjek Penelitian mahasiswa Fakultas Kedokteran Universitas Riau yang berada pada periode remaja akhir berusia 17-20 yang memenuhi kriteria inklusi ekslusi. Adapun teknik penelitian data dalam penelitian ini menggunakan data primer dan data sekunder.

Alat yang digunakan pada penelitian ini yaitu berupa timbangan digital dan mikrotoa untuk mengukur tinggi badan. Data dikumpulkan dengan menjawab kuesioner yang berupa daftar pertanyaan yang diisi sendiri oleh responden setelah diberi penjelasan oleh peneliti yang berupa : kuesioner identitas diri, kuesioner perilaku diet (eating attitude test)/ EAT-26., kuesioner body image silhouttes, dan kuesioner kualitas hidup WHO-QOL

Data yang telah dikumpulkan dalam kuesioner dilakukan pengeditan guna menghindari data yang kosong ataupun salah serta dilakukan pengkodean. Selanjutnya dilakukan entri data dengan menggunakan iystem komputerisasi guna pengolahan dan analisis data univariat. ${ }^{9}$

\section{HASIL}

Penelitian ini telah dilakukan pada seluruh mahasiswa remaja akhir angkatan 2012 yang berada pada rentang usia 17-20 tahun dengan jumlah responden 87 orang. Adapun karakteristik responden yang dinilai adalah jenis kelamin, body image, status gizi, perilaku diet, dan kualitas hidup. Untuk lebih jelas dapat dilihat pada tabel 1 .

Tabel 1. Karakteristik responden berdasarkan jenis kelamin, status gizi, body image, dan perilaku diet

\begin{tabular}{lcc}
\hline Variabel & Jumlah & Frekuensi (\%) \\
\hline Jenis kelamin & & \\
$\quad$ Laki- laki & 22 & 25,3 \\
Perempuan & 65 & 74,7 \\
Status gizi & & \\
IMT & & \\
$\quad$ Underweight & 15 & 17,2 \\
$\quad$ Normal & 48 & 55,2 \\
Overweight & 11 & 12,6 \\
Obesitas & 13 & 15 \\
Lingkar Perut & & \\
Obes & 22 & 25,3 \\
$\quad$ Non Obes & 65 & 74,7 \\
Citra Tubuh & & \\
Thin & 32 & 36,8 \\
$\quad$ Normal & 37 & 42,5 \\
Overweight & 17 & 19,5 \\
Obesitas & 1 & 1,2 \\
$\quad$ Tidak Puas & 45 & 51,7 \\
Puas & 42 & 48,3 \\
Perilaku Diet & & \\
$\quad$ Kemungkinan ada gangguan perilaku makan & 8 & 9,2 \\
Tidak ada gangguan perilaku makan & 79 & 90,8 \\
Kualitas Hidup & & \\
$\quad$ Kualitas Hidup Kurang & 38 & 43,7 \\
$\quad$ Kualitas Hidup Baik & 49 & 56,3 \\
\hline
\end{tabular}

\section{PEMBAHASAN}

Setelah dilakukan penelitian dengan jumlah responden berjumlah 87 orang yang terdiri dari 22 laki-laki dan 65 perempuan. Pada penelitian ini 
perbandingan jumlah responden laki-laki dan perempuan tidak sama dikarenakan proses pengambilan sampel dilakukan menggunakan metode total sampling, sehingga tidak didapatkan perbandingan yang sama antara jumlah responden laki-laki dan perempuan.

Status gizi responden pada penelitian ini didapatkan responden dengan status gizi terdapat status gizi lebih (overweight dan obesitas) sebesar 27,6\%, status gizi kurang (underweight) $17,2 \%$. Berdasarkan indikator lingkar perut terdapat 25,3\% subjek yang mengalami obesitas. Data Riskesdas tahun 2010 di Provinsi Riau status gizi penduduk di atas usia 18 tahun yang memiliki status gizi lebih dan obes persentasinya sebanyak $21,4 \%$. Hasil penelitian ini menunjukkan terjadi peningkatan persentasi gizi lebih pada remaja akhir jika dibandingkan dengan data Riskesdas Provinsi Riau tahun $2010 .{ }^{10} \mathrm{Hal}$ ini kemungkinan karena perbedaan jumlah sampel yang menjadi sampel pada penelitian ini serta cakupan wilayah pengambilan sampel. Prevalensi kegemukan pada remaja di perkotaan persentasinya lebih tinggi dibandingkan dengan di pedesaan. Prevalensi kekurusan persentasinya lebih tinggi pada remaja yang tinggal di pedesaan dibandingkan dengan remaja yang tinggal di perkotaan. ${ }^{10}$

Pada penelitian ini ditemukan body image overweight hampir 2,5 kali lebih besar dibandingkan dengan status gizi overweight pada responden yaitu $28,7 \%$ dengan $11,5 \%$. Hal ini juga ditemukan pada penelitian yang dilakukan pada remaja SMA di Bali dimana body image gemuk sebesar 20,4\% sedangkan status gizi lebih responden hanya $7,4 \%{ }^{11}$ Ketidakpuasan terhadap bentuk tubuh akan membentuk body image yang negatif (persepsi yang tidak sesuai dengan status gizi). ${ }^{12}$

Perilaku diet responden pada penelitian ini didapatkan yang memiliki kemungkinan ada gangguan perilaku makan sebesar 9,2\% dari total jumlah responden 87 orang. Penelitian pada mahasiswi FK USU tahun 2010 didapatkan sebesar $8 \%$ responden memiliki resiko gangguan makan. ${ }^{13}$ Angka ini menunjukkan pada saat ini remaja memiliki kemungkinan untuk mengalami gangguan perilaku makan. Hal ini mungkin dikarenakan arus informasi yang berkembang dan penilaian terhadap bentuk dan ukuran tubuh yang diterima masyarakat adalah bentuk tubuh yang ideal seperti role models iklan, sehingga mendorong mereka untuk melakukan diet. Remaja baik laki-laki maupun perempuan saat ini cenderung memperhatikan bentuk fisik mereka, terlebih pada remaja perempuan. Remaja perempuan menginginkan tubuh yang langsing sedangkan remaja laki-laki mengingingkan tubuh yang berotot dan tidak gemuk. Keinginan ini mendorong mereka untuk melakukan diet. $^{14,15}$

Pada penelitian ini didapatkan kemungkinan ada gangguan perilaku makan pada 9,2\% responden. Penelitian ini tidak untuk mendiagnosis suatu penyakit kelainan gangguan makan, namun dengan penelitian ini dapat mendeteksi adanya risiko berkembangnya perilaku diet yang tidak sehat menjadi gangguan makan pada remaja. Sebaiknya responden yang memiliki kemungkinan ada gangguan makan berkonsultasi ke Psikolog/ Psikiater.

\section{KESIMPULAN DAN SARAN}

\section{Kesimpulan}

Berdasarkan hasil penelitian diperoleh kesimpulan sebagai berikut:

1. Dari 87 responden terdapat 25,3\% (22) subjek laki-laki dan 74,7 \% (65) subjek perempuan dengan persentasi status gizi berdasarkan kategori IMT, terdapat status gizi lebih (overweight dan obesitas) sebesar 27,6\%, status gizi kurang (underweight) 17,2\%. Berdasarkan indikator lingkar perut terdapat 25,3\% subjek yang mengalami obesitas.

2. Terdapat $51,7 \%$ subjek penelitian yang merasa tidak puas dengan citra tubuhnya. Sebanyak 36,8\% subjek penelitian mempersepsikan tubuh mereka kurus, 19,5\% mempersepsikan overweight, dan 1,2 \% mempersepsikan citra tubuh obes.

3. Sebanyak 8 orang subjek penelitian $(9,2 \%)$ mengalami kemungkinan ada gangguan perilaku makan

4. Terdapat $43,7 \%$ subjek penelitian yang memiliki kualitas hidup yang kurang.

\section{Saran}

1. Diharapkan pada siswa yang memiliki 
kemungkinan gangguan perilaku makan untuk berkonsultasi kepada psikolog/ psikiater.

2. Diharapkan orang tua berperan aktif untuk mencontoh agar tidak membudayakan pola hidup yang sedentary seperti lebih banyak aktifitas fisik, tidak mengandalkan semua pekerjaan rumah pada pembantu.

3. Dilakukan penelitian lebih lanjut mengenai faktor resiko gangguan perilaku makan pada remaja.

\section{DAFTAR PUSTAKA}

1. Delamater, JL. (2002) A Study ti Determine The Effect of The Media on The Perception of Adolescents Female Body Image and The Resultant Relationship to Academic Achievement

2. Behrman RE, Klieman R, Arvin AM. Ilmu Kesehatan Anak Nelson (S. Wahab,et. Al,trans, S.Wahab,ed) $15^{\text {th }}$ Ed. Vol 1. Jakarta: EGC. (Original Book Published). p:73-8. 2000.

3. Findlay S. Dieting in adolescence. Paediatric Child Health. Canadian Paediatric Society. 2004; 9(7): 487-9.

4. Hurlock EB. Psikologi perkembangan suatu pendekatan sepanjang rentang kehidupan. Jakarta: Erlangga; 1980.

5. Mays, R.M.,Donald P.O. Psychosocial Development. Adolescent Nutrition

Assesment and Management. New York :Chapman \& Hall.109-122;1996.

6. Jennifer L. Derenne, M.D. and Eugene V. Beresin, M.D. Body Image, Media, and Eating Disorders. Acad Psychiatry2006; 30:257-261,
May-June

7. Schwimmer, J.B., Burwinkle, T.M. \& Varni, J.W. (2003) Health-related quality of life of severely obese children and adolescents. JAMA, 289, pp. 1813-19.

8. WHO (1997) WHOQOL : measuring quality of life, Geneva.

9. Notoatmodjo S. Metode penelitian kesehatan. Jakarta: Rineka Cipta; 2002.

10.Jennifer LD, Eugene VB. Body image, media, and eating disorders. Acad Psychiatry. Vol. 30. 2006. p. 257-261.

11.Badan penelitian dan pengembangan kesehatan kementrian kesehatan RI 2010.http:// www.riskesdas.litbang.depkes.go.id/ download/TabelRiskesdas2010. [diakses 16 November 2012]

12.National Eating Disorders Association. Citra tubuh and Eating Disorders; 2005. www.nationaleatingdisorders.org

13.Loke, K.Y. (2002) Consequences of childhood and adolescent obesity. Asia Pacific J Clin Nutr, 11(3), pp. S702-S704.

14.Gibson, RS. Principles of Nuutritional Assesment. New York: Oxford University Press;2005.

15.Felce, D. \& Perry, J. (1995) Exploring current conceptions of quality of life. In: Renwick, R. eds. Quality of life in health promotion and rehabilitation: conceptual approaches, issues and applications. London: Sage Publications, pp. 51-62. 